\title{
Configurações
}

Revista de sociologia

\section{Os modos de ser da informalidade: rumo a uma nova era da precarização estrutural do trabalho?}

The being modes of informality: towards a new era of the structural casualization of labour?

Les modes d'être de l'informalité : vers une nouvelle aire de précarité structurelle du travail?

\section{Ricardo Antunes}

\section{(2) OpenEdition}

\section{Journals}

Edição electrónica

URL: http://journals.openedition.org/configuracoes/230

DOI: $10.4000 /$ configuracoes.230

ISSN: 2182-7419

\section{Editora}

Centro de Investigação em Ciências Sociais

\section{Edição impressa}

Data de publição: 30 Junho 2010

Paginação: 155-166

ISSN: 1646-5075

\section{Refêrencia eletrónica}

Ricardo Antunes, «Os modos de ser da informalidade: rumo a uma nova era da precarização estrutural do trabalho? », Configurações [Online], 7 | 2010, posto online no dia 18 fevereiro 2012, consultado o 02 maio 2019. URL : http://journals.openedition.org/configuracoes/230 ; DOI : 10.4000/ configuracoes. 230

Este documento foi criado de forma automática no dia 2 Maio 2019.

(c) CICS 


\title{
Os modos de ser da informalidade: rumo a uma nova era da precarização estrutural do trabalho?
}

\author{
The being modes of informality: towards a new era of the structural \\ casualization of labour? \\ Les modes d'être de l'informalité : vers une nouvelle aire de précarité \\ structurelle du travail?
}

Ricardo Antunes

I

1 O mundo do capital, desde sua gênese, estampou um claro sentido destrutivo em relação ao trabalho, sem deixar de acentuar que este traço de superfl uidade e destrutividade também afetou diretamente a natureza e, sob forma ainda mais perversa, a destruição através da guerra, dentre tantos outros elementos que conformam seus traços atuais.

2 No que concerne mais diretamente ao trabalho, é também evidente que as formas atuais de valorização do valor trazem embutidas novos modos de geração da mais -valia (sob a forma absoluta e/ou relativa), ao mesmo tempo que expulsa da produção uma infi nitude de trabalhos que se tornam sobrantes, descartáveis e cuja função passa a ser a de expandir o bolsão de desempregados, deprimindo ainda mais a remuneração da força de trabalho em amplitude global, pela via da retração do valor necessário à sobrevivência dos trabalhadores e das trabalhadoras.

3 No volume III de 0 Capital, dentre tantas outras partes em que tratou da temática, ao discorrer sobre a economia no emprego e a utilização dos resíduos da produção, Marx pode indicar essa tendência ainda uma vez mais de modo cabal. Em suas palavras:

o capital tem a tendência a reduzir ao necessário o trabalho vivo diretamente empregado, a encurtar sempre o trabalho requerido para fabricar um produto - 
explorando as forças produtivas sociais do trabalho - e portanto a economizar o mais possível o trabalho vivo diretamente aplicado. Se observamos de perto a produção capitalista, abstraindo do processo de circulação e da hipertrofia da concorrência, verificamos que procede de maneira extremamente parcimoniosa com o trabalho efetuado, corporificado em mercadorias. Entretanto, mais do que qualquer outro modo de produção, esbanja seres humanos, desperdiça carne e sangue, dilapida nervos e cérebro. Na realidade, só malbaratando monstruosamente o desenvolvimento individual assegura -se e realiza -se o desenvolvimento da humanidade na época histórica que precede a fase em que se reconstituirá conscientemente a sociedade humana. Todas as parcimônias de que estamos tratando decorrem do caráter social do trabalho, e é de fato esse caráter diretamente social do trabalho a causa geradora desse desperdício de vida e da saúde dos trabalhadores. (Marx, 1974, pp. 97 e 99)

4 Premonitória, podemos adicionar que, em plena eclosão da mais recente crise global, este quadro se amplia ainda mais e nos faz presenciar uma corrosão ainda maior do trabalho contratado e regulamentado, que foi dominante ao longo do século $\mathrm{XX}$, de matriz tayloriano -fordista. Pautado pela subsunção real do trabalho (Marx, 1978) ao mundo maquínico, seja pela vigência da máquina-ferramenta autômata ou informacional -digital, este trabalho relativamente mais formalizado vem sendo substituído pelos mais distintos e diversificados modos de informalidade e precarização, de que são exemplo o trabalho atípico (Vasapollo, 2005), os trabalhos terceirizados (com sua enorme gama e variedade), o “cooperativismo", o “empreendedorismo", o "trabalho voluntário", etc.

5 Estas modalidades de trabalho - configurando as mais distintas e diferenciadas formas de precarização do trabalho e de expansão da informalidade - vêm ampliando as formas geradoras do valor, ainda que sob a aparência do não-valor, utilizando -se de novos e velhos mecanismos de intensifi cação (quando não de auto -exploração do trabalho).

6 Seria necessário recordar que, em pleno século XXI, há jornadas de trabalho, em São Paulo, que chegam a dezessete horas de trabalho por dia, na indús-tria de confecção, através de trabalhadores imigrantes bolivianos ou peruanos controlados por patrões coreanos ou chineses, aflorando um traço pouco visível e brutal da chamada "globalização", que configura modalidades de trabalho imigrante no limite da condição degradante?

7 Ou a profusão de exemplos de trabalho no agronegócios do açúcar, onde cortar mais de dez toneladas de cana por dia é a media em São Paulo, sendo que no Nordeste do país esse número pode chegar até dezoito toneladas diárias.

8 Ou ainda o acintoso exemplo do Japão, onde jovens operários de várias partes do país e do exterior migram em busca de trabalho nas cidades e dormem em cápsulas de vidro, do tamanho de um caixão, configurando o que denominei como operários encapsulados. No outro lado do mundo, aqui na nossa América Latina, mulheres trabalhadoras domésticas chegam a realizar jornadas de noventa horas por semana, tendo não mais que um dia de folga ao mês, conforme lembrou Mike Davis, em seu Planeta Favela (Davis, 2006).

9 Trata -se, portanto, de uma destrutividade que se expressa intensamente quando descarta, tornando ainda mais supérflua, parcela significativa da força mundial de trabalho, onde milhões encontram -se realizando trabalhos parciais, precarizados, na informalidade ou desempregados. Isso porque, na eliminação/ utilização dos resíduos da produção, o capital desemprega cada vez mais trabalho estável, substituindo -os cada vez mais por trabalhos precarizados, que se encontram em enorme expansão no mundo agrário, industrial e de serviços, bem como nas múltiplas interconexões existentes entre 
eles, como na agroindústria, nos serviços industriais ou na indústria de serviços. A eclosão generalizada do desemprego estrutural em escala transnacional é a expressão limite mais aguda e trágica desta destrutividade presente no mundo do trabalho. ${ }^{1}$

10 Como, entretanto, o capital não pode valorizar-se, isto é, gerar mais -valor, sem realizar alguma forma de interação entre trabalho vivo e trabalho morto, ele busca incessantemente o aumento da produtividade do trabalho, ampliando os mecanismos de extração do sobretrabalho em tempo cada vez menor, através da ampliação do trabalho morto corporificado no maquinário tecno-científico -informacional.

11 A informalização do trabalho torna -se, então, um traço constitutivo e crescente da acumulação de capital dos nossos dias, uma vez que se torna cada vez mais permanente na fase da liofi lização organizativa, para retomar a sugestão de Juan J. Castillo, 1996. Compreender seus modos de expressão e seus significados é, então, importante para que possamos ter uma melhor compreensão dos mecanismos e das engrenagens que impulsionam o mundo do trabalho em direção à informalidade.

\section{II}

12 Uma fenomenologia preliminar dos modos de ser da informalidade demonstra a ampliação acentuada de trabalhos submetidos a sucessivos contratos temporários, sem estabilidade, sem registro em carteira, trabalhando dentro ou fora do espaço produtivo das empresas, quer em atividades mais instáveis ou temporárias, quando não na condição de desempregado. $^{2}$

13 Uma primeira modalidade de informalidade remete à figura dos trabalhadores informais tradicionais, "inseridos nas atividades que requerem baixa capitalização, buscando obter uma renda para consumo individual e familiar. Nesta atividade, vivem de sua força de trabalho, podendo se utilizar do auxílio de trabalho familiar ou de ajudantes temporários (Alves e Tavares, 2006).

14 Neste universo encontramos “os menos 'instáveis', que possuem um mínimo de conhecimento profissional e os meios de trabalho e, na grande maioria dos casos, desenvolvem suas atividades no setor de prestação de serviços", de que são exemplos costureiras, pedreiros, jardineiros, vendedores ambulantes de artigos de consumo mais imediato como alimentos, vestuário, calçados e de consumo pessoal, camelôs, empregados domésticos, sapateiros e ofi cinas de reparos (ibidem).

Há também os informais mais "instáveis", recrutados temporariamente e freqüentemente remunerados por peça ou por serviço realizado. Eles fazem trabalhos eventuais e contingenciais, pautados pela força física e pela realização de atividades dotadas de baixa qualificação, como carregadores, carroceiros e trabalhadores de rua e serviços em geral. Estes trabalhadores mais "instáveis" podem inclusive ser subempregados pelos trabalhadores informais mais "estáveis" (ibidem).

16 Nesta primeira modalidade - trabalhadores informais tradicionais - podemos incluir os trabalhadores "ocasionais" ou "temporários", que realizam atividades informais quando se encontram desempregados, mas que visam retornar ao trabalho assalariado. Segundo a caracterização de Alves e Tavares (2000), "são trabalhadores que ora estão desempregados, ora são absorvidos pelas formas de trabalho precário, vivendo uma situação que, inicialmente, era provisória e se transformou em permanente. Há casos que combinam o trabalho regular com o ocasional, praticando os chamados bicos. Nesses casos 
obtém -se um baixo rendimento com essas atividades", como os "vendedores de diversos produtos (limpeza, cosméticos, roupas), digitador, salgadeiras, faxineiras e confecção de artesanato nas horas de folga". Ainda neste espectro de atividades informais tradicionais encontram -se as pequenas oficinas de reparação e concertos, estruturadas e mantidas pela clientela do bairro ou relações pessoais. (ibidem). Inseridos na divisão social do trabalho capitalista, essa gama de trabalhadores informais "contribui para que se efetive a circulação e consumo das mercadorias produzidas pelas empresas capitalistas. A forma de inserção no trabalho informal é extremamente precária e se carateriza por uma renda muito baixa, além de não garantir o acesso aos direitos sociais e trabalhistas básicos, como aposentadoria, FGTS, auxílio -doença, licença maternidade; se fi carem doentes são forçados a parar de trabalhar, perdendo integralmente sua fonte de renda" (ibidem).

Não há horário fixo de trabalho e as jornadas de trabalho levam freqüentemente ao uso das horas vagas para aumentar a renda oriunda do trabalho. Acrescente -se ainda o fato de que, no trabalho por conta -própria, além do uso de seu trabalho, pode haver uso da força de trabalho de outros membros da família, com ou sem remuneração.

Uma segunda modalidade remete à fi gura dos trabalhadores informais assalariados sem registro, ao arrepio da legislação trabalhista, uma vez que perderam o estatuto de contratualidade e que passam da condição de assalariados com carteira assinada para a de assalariados sem carteira, excluindo -se do acesso das resoluções presentes nos acordos coletivos de sua categoria (Ibidem). A indústria de têxtil, de confecções e de calçados, por exemplo, dentre tantas outras, tem acentuado esta tendência (Antunes, 2006).

Isto porque a racionalidade instrumental do capital impulsiona as empresas à flexibilização do trabalho, da jornada, da remuneração, aumentando a responsabilização e as competências, criando e recriando novas relações e formas de trabalho que freqüentemente assumem feição informal. Nos exemplos de Alves e Tavares (2006) encontram -se "(..) os casos de trabalho em domicílio que se especializam por áreas de ocupação, prestando serviços às grandes empresas, que também se utilizam da subcontratação para a montagem de bens, produção de serviços, distribuição de bens através do comércio de rua ou ambulante" (ibidem). Muitas vezes este modo de trabalho se realiza também em galpões - como na indústria de calçados -, onde a informalidade é a norma.

21 Uma terceira modalidade, encontramos nos trabalhadores informais por conta-própria, que podem ser definidos como uma variante de produtores simples de mercadorias, contando com sua própria força de trabalho ou de familiares e que podem inclusive subcontratar força de trabalho assalariada (ibidem).

22 Segundo Alves e Tavares (2006), as "formas de inserção do trabalhador por conta -própria na economia informal não são práticas novas, mas foram recriadas pelas empresas capitalistas, como forma de possibilitar a extração da mais -valia relativa com a mais valia absoluta. Lembramos que há diferentes formas de inserção do trabalho informal no modo de produção capitalista e, para sua análise, devemos considerar essa grande heterogeneidade, buscando desvendar quais os vínculos existentes entre esses trabalhadores e o acúmulo de capital".

23 E acrescentam: "Deste modo, proliferam -se os pequenos negócios vinculados às grandes corporações, envolvendo as áreas de produção, comércio e prestação de serviços. Os pequenos proprietários informais atuam em áreas que não atraiam investimentos 
capitalistas de maior vulto, de modo a atender à demanda por determinados bens $\mathrm{e}$ serviços. Esses trabalhadores adotam essas estratégias porque seus pequenos negócios informais não têm condições de concorrer com as empresas capitalistas, são elas que definem sua forma de inserção no mercado" (ibidem).

Estamos vivenciando, portanto, a erosão do trabalho contratado e regulamentado, dominante no século $\mathrm{XX}$, e vendo sua substituição pelas diversas formas tais como "empreendedorismo", "cooperativismo", "trabalho voluntário". o exemplo das cooperativas talvez seja ainda mais esclarecedor. Em sua origem, elas nasceram como instrumentos de luta operária contra o desemprego, o fechamento das fábricas, o despotismo do trabalho, como tantas vezes Marx indicou. Hoje, entretanto, contrariamente a essa autêntica motivação original, os capitais criam falsas cooperativas como instrumental importante para depauperar ainda mais as condições de remuneração da força de trabalho e aumentar os níveis de exploração da força de trabalho, fazendo erodir ainda mais os direitos do trabalho.

As "cooperativas" patronais tornam -se, então, contemporaneamente, verdadeiros empreendimentos visando aumentar ainda mais a exploração da força de trabalho e a conseqüente precarização da classe trabalhadora. Similar é o caso do "empreendedorismo", que cada vez mais se configura como forma oculta de trabalho assalariado e que permite o proliferar das distintas formas de fl exibilização salarial, de horário, funcional ou organizativa.

É neste quadro, caracterizado por um processo tendencial de precarização estrutural do trabalho, em amplitude ainda maior, que os capitais globais estão exigindo também o desmonte da legislação social protetora do trabalho. E fl exibilizar a legislação social do trabalho significa - não é possível ter nenhuma ilusão sobre isso - aumentar ainda mais os mecanismos de extração do sobretrabalho, ampliar as formas de precarização e destruição dos direitos sociais que foram arduamente conquistados pela classe trabalhadora, desde o início da Revolução Industrial, na Inglaterra, e especialmente pós -1930 , quando se toma o exemplo brasileiro.

III

Feito este desenho inicial, que apresenta algumas modalidades vigentes da informalidade hoje, vamos indicar analiticamente algumas teses que fundamentam esse múltiplo processo de informalização e de precarização da força humana de trabalho em escala global. O faremos a partir do enunciado de duas teses:

28 Primeiro, a que discorre sobre a falácia da "qualidade total" sob a vigência da lei de tendência decrescente do valor de uso das mercadorias e, segundo, a que apresenta a similitude existente entre o descarte do trabalho e a superfl uidade da produção em geral - tal como apresentamos na formulação marxiana que inicia este artigo - e que está presente nas práticas de liofi lização da chamada "qualidade total". ${ }^{3}$

$29 \mathrm{Na}$ presente fase de intensificação da taxa de utilização decrescente do valor de uso das mercadorias (Mészáros, 2002), a falácia da qualidade torna -se evidente e ela talvez possa ser formulada desse modo: quanto mais "qualidade total" as mercadorias e os produtos que resultam do processo produtivo capitalista alegam ter, menor é o seu tempo de duração.

30 A necessidade imperiosa de reduzir o tempo de vida útil dos produtos, visando aumentar a velocidade do ciclo reprodutivo do capital, faz com que a "qualidade total" seja, na 
maior parte das vezes, o invólucro, a aparência ou o aprimoramento do supérfl uo, uma vez que os produtos devem durar cada vez menos para que tenham uma reposição ágil no mercado. A "qualidade total", por isso, deve se adequar ao sistema de metabolismo sócio reprodutivo do capital, afetando tanto a produção de bens e serviços, como as instalações, maquinários e a própria força humana de trabalho (Mészáros, 2002 e Antunes, 2009).

Desse modo, o apregoado desenvolvimento dos processos de "qualidade total" converte se na expressão fenomênica, involucral, aparente e supérfl ua de um mecanismo produtivo gerador do descartável e do supérfluo, real impedimento para a criação de uma sociedade efetivamente auto-sustentada, fora dos constrangimentos da reprodução ampliada do capital e seus imperativos expansionistas e destrutivos.

Além do exemplo emblemático dos fast foods (do qual o McDonalds é exemplar), expressão simbólica da sociedade do entertainment propiciada pelo capital, podemos lembrar também do tempo médio de vida útil estimada para os automóveis mundiais, cuja durabilidade é cada vez mais reduzida.

Recentemente, vimos a explosão do recall, que atingiu quase todas as grandes montadoras, como a Ford, GM, Fiat, sem deixar de mencionar o caso mais espetacular, o recente recall da Toyota, nos inícios de 2010, quando milhares de veículos foram produzidos por uma peça que tinha claro componente propiciador de acidentes que em certos casos - e não foram poucos - foram letais, ocasionando a ampliação da crise na "montadora da qualidade total" em sua unidade nos EUA. O próprio presidente da Toyota teve que se desculpar no parlamento norte -americano, como se isso em alguma medida repusesse as perdas humanas.

Laboratório de uma qualidade que destrói a longevidade, de um invólucro que converte os consumidores em cobaias dos inventos feitos a qualquer preço, esse exemplo estampa a tendência destrutiva presente no âmago da chamada "qualidade total", que tem que conviver com a redução tendencial do tempo de vida útil das mercadorias (Mészáros, 2002), para incrementar (destrutivamente) o processo de valorização do capital.

Portanto, as empresas, na competitividade exacerbada que travam entre si para avançar na guerra da "produtividade de perfil destrutivo", são impelidas a reduzir o tempo entre produção e consumo, incentivando ao limite esta tendência restritiva do valor de uso das mercadorias.

36 Tendo que acompanhar - e vencer para sobreviver - a competitividade existente em seu ramo produtivo, os capitais desencadeiam uma lógica na qual a busca da "qualidade total" é um mecanismo intrínseco e funcional, redutor do ciclo de vida útil dos produtos, ainda que tenha a aparência (no sentido dado por Marx) do avanço real da qualidade (sem aspas).

37 Podemos também mencionar a indústria de computadores, expressão desta tendência depreciativa e decrescente do valor de uso das mercadorias, onde um sistema de softwares torna -se obsoleto e desatualizado em tempo reduzido, obrigando o consumidor a adquirir a nova versão ou perder seu maquinário quando tem que fazer uma reposição, pois o custo de uma peça a ser trocada freqüentemente excede o preço de um novo equipamento, o que leva ao descarte precoce de uma máquina computacional.

Isso porque os capitais não têm outra opção, para sua sobrevivência, senão "inovar" ou correr o risco de serem ultrapassados pelas empresas concorrentes, conforme ocorre com as empresas transnacionais de computadores, onde, paralelamente à "inovação" 
constante de seu sistema, o tempo de vida útil dos produtos também se reduz enormemente. (Kenney, 1997)

Como o capital tem uma tendência expansionista intrínseca ao seu sistema produtivo, a "qualidade total" deve tornar-se inteiramente compatível com a lógica da produção supérflua e destrutiva. Por isso, em seu sentido e tendências mais gerais, o capitalismo, ao mesmo tempo que reitera sua suposta capacidade de elevação da "qualidade total", converte -se de fato em inimigo da durabilidade dos produtos; desencorajando e mesmo inviabilizando práticas produtivas orientadas para as reais necessidades humano -sociais (Mészáros, 2002).

Opõe -se, portanto, frontalmente à longevidade dos produtos e a denominada "qualidade total" acaba por converte r-se no seu contrário, isto é, na negação da durabilidade das mercadorias.

O resultado é visível quando se dissipa a bruma ideológica que sustenta esse engenhoso mecanismo: quanto mais "qualidade total" as mercadorias aparentam ter (e aqui novamente a aparência faz a diferença), mais reduzido é seu tempo de vida útil e menor é o tempo de duração que elas devem efetivamente conter. O desperdício, a superfluidade, a destrutividade e a obsolescência programada tornam -se caraterísticas determinantes da produção, seja ela material, seja imaterial. E o curioso é que, mergulhado nesta lógica destrutiva, nunca os capitais falaram tanto em sustentabilidade.

Como já pudemos indicar em Os Sentidos do Trabalho (Antunes, 2009), aqui não se está questionando o que seria um efetivo avanço tecno -científi co se este fosse pautado pelos reais imperativos humano -societais. Exatamente pela vigência da lógica destrutiva do capital, que plasma a forma da tecno -ciência contemporânea em sua razão instrumental, que os mecanismos e as engrena-gens do sistema de metabolismo sócio -econômico acabam por converter em descartável e supérfluo tudo que poderia ser preservado e reorientado, tanto para o atendimento efetivo dos valores de uso sociais, quanto para se evitar uma destruição incontrolável e degradante da natureza, do meio ambiente, da relação metabólica entre trabalho e natureza.

43 E algo similar vem ocorrendo no universo do trabalho, o que nos permite avançar na segunda tese, qual seja: a empresa da fl exibilidade liofi lizada tem uma impulsão intrínseca em direção ao aumento da superfl uidade do trabalho.

Isso porque o sistema de metabolismo social do capital necessita cada vez menos do trabalho estável e cada vez mais das diversificadas formas de trabalho parcial ou part-time, terceirizado, dos trabalhadores hifenizados, do cybertariado (Huws, 2003), do infoproletariado (Antunes e Braga, 2009), variantes do proletariado da era cyber, que se encontra em explosiva expansão em todo o mundo produtivo e de serviços.

Como o tempo e o espaço estão em freqüente mutação, nesta fase de mundialização do capital, a redução do proletariado taylorizado, especialmente nos núcleos mais avançados da indústria e a paralela ampliação do trabalho intelectual nas plantas produtivas onde esta modalidade de trabalho é requerida, caminham em clara inter-relação com a ampliação generalizada dos novos proletários, mais precarizados, terceirizados e informalizados, tanto na indústria, quanto na agricultura e nos serviços, além de suas áreas de evidente conexão, como a agro -indústria, a indústria de serviços e os serviços industriais.

Como o capital só pode reproduzir-se acentuando seu forte sentido de desperdício, é útil a síntese de Tosel, quando afirma que é a própria "centralidade do trabalho abstrato que produz a não -centralidade do trabalho, presente na massa dos excluídos do trabalho 
vivo" que, uma vez (des)socializados e (des) individualizados pela expulsão do trabalho, "procuram desesperadamente encontrar formas de individuação e de socialização nas esferas isoladas do não-trabalho (atividade de formação, de benevolência e de serviços)" (Tosel, 1995, p. 210)

Como pude sintetizar recentemente, ao apresentar a revista Katálysis (2009): "Em verdade, intensifi caram -se e ampliaram -se as formas geradoras do valor, articulando um maquinário altamente avançado (de que são exemplo as tecnologias de comunicação e informação que invadiram o mundo da mercadoria) com a exigência, feita pelos capitais, de buscar maiores 'qualifi cações' e 'competências' da força de trabalho (seja aquela de perfi 1 acentuadamente manual ou a que exercita uma destreza quase artesanal na era informacional do capital, além do contingente de trabalho humano fornecedor de maior potencialidade intelectual, aqui entendida em seu restrito sentido dado estritamente pelo mercado, e que se integra no trabalho social complexo, e combinado, de que falava Marx".

É como se todos os espaços possíveis fossem potencialmente convertidos em geradores de mais -valor, desde aqueles que ainda mantêm laços de formalidade e contratualidade, até aqueles que se pautam pela mais pura informalidade, na franja integrada ao sistema, não importa que sejam atividades predominantemente manuais ou aquelas acentuadamente responsáveis por atividades consideradas (sempre pelo olhar do mercado) como mais "intelectualizadas", "dotadas de conhecimento", o que deu vitalidade e contemporaneidade, ao invés de depauperar, a teoria do valor-trabalho. ${ }^{4}$

século XX, presenciamos a vigência da era da degradação do trabalho, nas últimas décadas do século XX e início do XXI, estamos defronte a outras modalidades e modos de ser da precarização, próprias da fase da fl exibilidade toyotizada, com seus traços de continuidade e descontinuidade em relação à forma tayloriano -fordista.

50 A título de hipótese, que estamos explorando mais recentemente em nossa pesquisa, podemos sugerir ao menos duas formas mais gerais que desenham o que venho denominando como precarização estrutural do trabalho.

51 A primeira, de base tayloriano-fordista, é mais acentuadamente despótica, embora mais regulamentada e contratualista. 0 trabalho é mais coisifi cado e reificado, maquinal, embora provido de direitos e de regulamentação social. É uma modalidade de trabalho coisificada de tipo regulamentado, tão ricamente explorada por Lukács em seu História e Consciência de Classe e por Gramsci em seu ensaio Americanismo e Fordismo, ambos seminais.

52 A segunda forma de degradação do trabalho advém da implantação do que denomino como $f$ exibilidade liofi lizada, aparentemente mais "participativa", mas cujos traços de estranhamento e reificação são mais interiorizados do que aqueles vigentes no período precedente. Sem deixar de mencionar o fato de que a era da fl exibilidade liofi lizada é responsável pela desconstrução monumental dos direitos sociais do trabalho e pela generalização das novas modalidades da precarização.

53 As "responsabilizações" e as "individualizações", os "parceiros" ou "consultores", os "envolvimentos" dos novos "colaboradores", as "metas" e "competências" que povoam o universo discursivo do capital são, portanto, traços fenomênicos, encobridores de uma acentuada informalização e precarização do trabalho.

54 Sem querer esboçar uma fenomenologia da subjetividade, que pudesse tornar mais inteligíveis as bases sócio -históricas do fenômeno da alienação ou do estranhamento na empresa capitalista contemporânea, vale ao menos remeter às inúmeras possibilidades analíticas existentes a partir da diferenciação sugerida por Lukács, na sua obra de 
maturidade a Ontologia do Ser Social, e recuperada por Tertulian, entre as reifi cações "inocentes" e as reificações "alienantes", que aqui não podemos desenvolver ${ }^{5}$ (Ver Tertulian, 1993 e Lukács, 1981).

Estamos, portanto, frente a uma nova fase de desconstrução do trabalho sem precedentes em toda era moderna, ampliando os diversos modos de ser da informalidade e da precarização do trabalho. Avançando na formulação, no atual contexto de crise estrutural do capital, parece que estamos adentrando numa nova era de precarização estrutural do trabalho em escala global. ${ }^{6}$

Ou seja, no movimento pendular do trabalho, preservados os imperativos destrutivos do capital, oscilamos crescentemente entre a perenidade de um trabalho cada vez mais reduzido, intensificado e mais explorado, dotado de direitos, e, de outro, uma superfluidade crescente, cada vez mais geradora de trabalho precarizado e informalizado, como via de acesso ao desemprego estrutural.

Em outras palavras, labor mais qualificado para um contingente cada vez mais reduzido e um labor cada vez mais instável e precarizado para um universo cada vez mais ampliado de trabalhadores e trabalhadoras. Ora intensifi cando intelectual e/ou manualmente os trabalhos dos que se encontram no mundo da produção, ora expulsando enormes contingentes de assalariados que não têm mais possibilidade real de serem incorporados e absorvidos pelo capital e que se somam às fileiras do bolsão de desempregados.

Que, entretanto, cumprem papel ativo no ciclo de valorização do valor, especialmente pela criação de um enorme excedente de força de trabalho que subvaloriza quem se mantém no universo do trabalho assalariado.

Por fim, é preciso enfatizar que a informalidade, em seus distintos modos de ser - que aqui tão-somente indicamos alguns exemplos - supõe sempre a ruptura com os laços de contratação e regulação da força de trabalho, tal como se estruturou a relação capital e trabalho especialmente ao longo do século XX, sob a vigência tayloriano-fordista, quando o trabalho regulamentado tinha prevalência sobre o desregulamentado.

60 Se a informalidade não é sinônimo direto de precariedade, sua vigência expressa formas de trabalho desprovido de direitos e, por isso, encontra clara similitude com a precarização. Se a boa teoria e a cuidadosa reflexão não devem borrar conceitos e categorias que são assemelhados e similares (mas não necessariamente idênticos), apontar suas conexões, suas inter-relações e suas vinculações torna -se, entretanto, imprescindível.

61 Assim, neste universo categorial e analítico, poder-se -ia concluir acrescentando que a flexibilização e a informalização da força de trabalho são caminhos seguros, utilizados pela engenharia do capital, para arquitetar e ampliar a intensifi cação, a exploração e, last but not least, a precarização estrutural do trabalho em escala global.

\section{BIBLIOGRAPHY}

ANTUNES, Ricardo (2009). Os Sentidos do Trabalho (Ensaio sobre a Afirmação e a Negação do Trabalho), Ed. Boitempo, 11.' edição, São Paulo. 
_- (2005). O Caracol e sua Concha (Ensaios sobre a Nova Morfologia do Trabalho, Boitempo.

_-- (organizador, 2006). Riqueza e Miséria do Trabalho no Brasil, Boitempo.

_-, Revista Katálysis, Vol. 12, julho/dezembro -2009, UFSC.

ANTUNES, Ricardo e BRAGA, Ruy, (2009a). Infoproletários (Degradação Real do Trabalho Virtual), Boitempo.

CASTILLO, Juan J. (1996). Sociologia del Trabajo, CIS, Madri.

DAVIS, Jim, HIRSCHL, Thomas e STACK, Michael (1997). Cutting Edge: Technology, Information, Capitalism and Social Revolution, Verso, Londres/Nova Iorque.

DAVIS, Mike (2006). Planeta Favela, Boitempo, São Paulo.

HUWS, Ursula (2003). The Making of a Cybertariat (virtual work in a real world), Monthly Review Press/The Merlin Press, Nova Iorque/Londres.

KENNEY, Martin (1997). "Value Creation in the Late Twentieth Century: The Rise of the Knowledge Worker”, in DAVIS, Jim, op. cit. LUKÁCS, Georg (1981). Ontologia Dell'Essere Sociale II, Vol. 1 e 2, Ed. Riuniti, Roma.

MARX, K. (1974). O Capital, Ed. Civilização Brasileira, Rio de Janeiro.

MARX, K. (1978). Capítulo VI (Inédito), Ed. Ciências Humanas, SP.

MÉSZÁROS, István 2002). Para Além do Capital, Ed. Boitempo.

TOSEL, André (1995). “Centralité et non -centralité du travail ou la passion des hommes superfl us", in BIDET, Jacques e TEXIER, Jacques (1995) La Crise du travail, Actuel Marx Confrontation, Presses Universitaires de France, Paris.

TERTULIAN, Nicolas (1993). “Le concept d'aliénation chez Heidegger et Lukács”', Archives de Philosophie - Reserches et Documentation 56, julho/setembro, Paris.

VASAPOLLO, L. (2005). O Trabalho Atípico e a Precariedade, Ed. Expressão Popular, São Paulo.

\section{NOTES}

1. Um traço preocupante deste cenário vimos recentemente em uma manifestação de trabalhadores britânicos em greve, no início de 2009, que estampava em seus cartazes os seguintes dizeres: "Put British Workers First" (Empreguem primeiro os trabalhadores britânicos), em manifestação contrária à contratação de italianos e portugueses. Se é justa a consigna de salário igual para trabalho igual, também é muito preocupante a manifestação que pode conter traços xenofóbicos contra trabalhadores portugueses, italianos ou poloneses.

2. Em Riqueza e Miséria do Trabalho no Brasil, há um desenho das características principais da informalidade, que utilizaremos a seguir, feita por Alves e Tavares. (Antunes, 2006).

3. Retomamos aqui duas teses originalmente apresentadas em Os Sentidos do Trabalho, Boitempo, 10. ${ }^{a}$ reimpressão, revista e atualizada.

4. No que segue, retomo algumas idéias apresentadas na minha apresentação à revista Katálysis, op. cit.

5. As reificações inocentes manifestam -se quando ocorre a condensação das atividades em um objeto, em uma coisa, propiciando a "coisificação" das energias humanas, que funcionam como re fl exos condicionados e que acabam por levar às reificações "inocentes”. A subjetividade é reabsorvida no funcionamento do objeto, sem efetivar-se uma "alienação" propriamente dita (Tertulian, 1993, p. 441). As reificações "alienadas" ocorrem quando a subjetividade é 
transformada em um objeto, em um "sujeito -objeto, que funciona para a auto-afirmação e a reprodução de uma força estranhada. O indivíduo que chega a auto-alienar suas possibilidades mais próprias, vendendo por exemplo sua força de trabalho sob condições que lhe são impostas, ou aquele que, em outro plano, sacrifica-se ao 'consumo de prestígio', imposto pela lei de mercado" (ibidem).

6. Uma rápida consulta aos dados acerca do desemprego mundial é sintomática. A OIT projetou mais de 50 milhões de desempregados, ao longo de 2009, em conseqüência da intensificação da crise que atingiu especialmente os países do Norte. E acrescentou que aproximadamente 1,5 bilhão de trabalhadores sofreriam redução em seus salários (Relatório mundial sobre salários 2008/2009). A América Latina não fi cou de fora deste cenário assustador: a OIT estimou que "até 2,4 milhões de pessoas" poderiam entrar nas fi las do desemprego em 2009, somando -se aos quase dezasseis milhões hoje desempregados, sem falar do "desemprego oculto" e outros mecanismos que mascaram as taxas reais de desemprego (Panorama Laboral para América Latina e Caribe, janeiro de 2009). Nos EUA, Inglaterra, Alemanha, Espanha, Portugal, Japão, dentre tantos outros países, os índices de desemprego são os maiores das últimas décadas.

\section{ABSTRACTS}

Como resultado das transformações e metamorfoses nos países capitalistas, estamos diante de um intenso e significativo processo de subproletarização - trabalho temporário e precarizado -, que, em suas diversas determinações, caracteriza o capitalismo atual. Estas metamorfoses não invalidam a lei do valor quando se considera a totalidade do trabalho, a capacidade de trabalho social-mente combinada, o trabalhador coletivo como uma expressão de múltiplas atividades combinadas. Em oposição à afirmação do fim do trabalho, podemos constatar uma expressiva precarização e informalidade do trabalho, que ocorre nas formas de trabalho parcial, subcontratado e precarizado.

As a result of the transformations and metamorphoses in the capitalist countries, we are in the presence of a significant process of intensive underproletarianisation - casual and temporary labour -, that, in its diverse determi nations, characterizes today capitalism. These metamor phoses do not deny the law of value when one considers the labour totality, the socially com bined labour capacity, the collective worker as an expression of multiple combined activities. Contrary to the affirmation of the end of labour, we observe an expressive casualization and informality of labour that occurs in the forms of partial, precarious and subcontracted labour.

L'objectif de cet article est de vérifier deux propositions théoriques qui essaient d'expliquer les variations observées dans la distribution des valeurs instrumentales et expressives du travail. D'un côté l'hypothèse du changement intergénérationnel, qui suppose qu'un changement de valeurs soit le résultat du remplacement des plus vieilles générations par les plus jeunes et, d'un autre côté, l'hypothèse qui affirme que le changement est déterminé par des facteurs relatifs au statut socio-économique de l'individu. Les données de dix pays européens montrent que l'hypothèse du changement intergénérationnel est inconsistante et renforcent l'importance du niveau d'études comme facteur explicatif des orientations de travail. 
INDEX

Mots-clés: métamorphoses du travail, précarisation du travail, sous-traitance, travail informel, loi de la valeur

Keywords: metamorphoses of labour, casualization of labour, subcontracting, informality of labour, law of value

Palavras-chave: metamorfoses do trabalho, precarização do trabalho, subcontratação, informalidade do trabalho, lei do valor

AUTHOR

RICARDO ANTUNES

Instituto de Filosofia e Ciências Humanas, Universidade Estadual de Campinas, Brasil. 